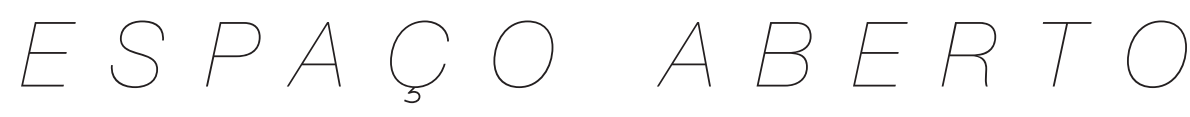

OLHARES DA CRIATIVIDADE SOBRE A VIDA DE CORA CORALINA

Fabiola Ribeiro de Souza ${ }^{1}$

\title{
resumo
}

Esse artigo, do tipo estudo biográfico, pretende divulgar algumas teorias sobre a criatividade, reunindo contribuições de autores no assunto, exemplificadas por relatos da vida da escritora Cora Coralina. Também objetiva chamar a atenção do leitor para a necessidade e a possibilidade de desenvolvimento da própria criatividade, ao longo da vida, visto que, segundo os estudos apresentados, é um potencial possível a todos. Deste modo é de expectativa da autora do artigo que os leitores possam se identificar com eventos da vida de Cora, bem como com as teorias apresentadas para compreender que mesmo as dificuldades e dores comuns à vida humana podem despertar e alimentar a criatividade. Também reforçar a importância do exercício da criatividade desde o início da vida até a longevidade, em especial quando exercida como algo prazeroso e com sentido para o crescimento do indivíduo como um todo, abrangendo aspectos intra e extra-pessoais.

palavras-chave:

Criatividade. Desenvolvimento. Cora Coralina. Longevidade.

1 Mestre em Educação com especialização em psicologia do Desenvolvimento, inclusão escolar e desenvolvimento de pessoas com Deficiência Intelectual pela Universidade Católica de Brasília (UCB). Professora de ensino especial em Deficiência Intelectual e responsável pelo processo de inclusão escolar de adolescentes com Deficiência Intelectual, no ensino fundamental das séries finais, da Secretaria de Educação do Distrito Federal (SEDF). E-mail: fabiquilt@ig.com.br 
Provavelmente, todo brasileiro já ouviu falar em Cora Coralina, poetisa goiana que alcançou reconhecimento no final do século passado, após os 70 anos de idade. Se também se perguntasse a seus leitores sobre o seu caráter criativo, poucos ousariam dizer o contrário. Entretanto, poderia a escritora ser considerada criativa à luz de teorias sobre o assunto? Este artigo demonstra tal possibilidade, fazendo um paralelo entre a biografia de Cora em consonância com estudos sobre criatividade.

Os relatos da vida da escritora foram extraídos da biografia escrita por uma de suas filhas, Vivencia Tahan (1989) apresentados em ordem cronológica e organizados em períodos que compreendem sua infância, adolescência, juventude, fase adulta e período da longevidade. Os fatos narrados dialogam com diferentes estudos, ou seja, os diversos olhares da criatividade a partir das contribuições teóricas de pesquisadores como Alencar e Fleith (2003), Amabile (1999), Barros e Búrigo (2005), Nakamura e Csikszentmihaly (2003) que abordam aspectos da criatividade concernentes aos traços de personalidade das pessoas criativas, o processo criativo, fatores externos de influência, motivação e, é claro, a criatividade no período da longevidade.

\section{OLHARES DA CRIATIVIDADE SOBRE A VIDA DE CORA CORALINA}

Infância

Da união entre Francisco de Paula Lins dos Guimarães e de Jacintha Luzia de Couto Brandão Peixoto nasce, na cidade de Goiás, Ana Lins dos Guimarães, em 20 de agosto de 1889. Enquanto bebê era tido como chorona, magra, e "doentinha". Já criança, gostava de brincar de faz de conta e de dar asas à fantasia, mas não gostava da escola por achar o ambiente opressor. Tida como aluna com dificuldades, goza apenas de dois anos de escolarização, mas aprende a ler e se delicia com os livros que sua mãe, leitora assídua, conservava. Ainda criança começa escrever versos.

É possível que a pouca frequência escolar tenha incidido positivamente na criação posterior de Cora, devido os moldes opressores que ela mesma traduz. Pesquisas demonstram que a educação formal, quando prioriza a 
reprodução e memorização, pode inibir o potencial criativo e inovador dos alunos (MARTINS; ALENCAR, 2011).

\section{Adolescência}

Na adolescência angustia-se ao ouvir comentário da família sobre sua ausência de beleza física e possível "solteirice", mas aos dezesseis anos, chega a uma importante conclusão que norteará sua vida: "Não vou mais me incomodar com isto. Tenho belezas dentro de mim e com elas vou viver" (TAHAN, 1989, p. 26). Também era criticada por seu interesse literário. Sua mãe alegava que era esta a razão de Ana ainda estar solteira. Da. Jacinta não era chamada de senhora por acaso. Criava as filhas debaixo de uma rigidez moral e religiosa da qual Ana desde cedo tentava se desvencilhar. Como ela mesma descreveu posteriormente, viveu sua vida removendo pedras e plantando flores. Ao invés de sucumbir às pressões externas e internas, suas frustrações, e até uma desilusão amorosa, eram contadas por seus escritos como gritos sublimes ou esquecidas na outra paixão que desenvolve: o cultivo de flores.

Apesar das adversidades, Cora continua a escrever. Freud afirmava que a criatividade pode surgir a partir da energia gerada por traumas e frustrações. Assim, o escritor pode se valer da fantasia para fugir de realidades opressoras ou para dar vazão a desejos reprimidos (ALENCAR; FLEITH, 2003).

\section{Juventude}

Felizmente, gozava do incentivo de um amigo de família, que a convidava para participar de eventos literários da cidade. Nestes momentos aproveitava para soltar um de seus poemas usando o nome de Cora e, também, envia alguns de seus escritos para um jornal local, em 1910.

As profecias de família sobre sua solidão não se cumprem e, aos 22 anos, se apaixona pelo advogado Cantídio, 23 anos mais velho que ela, porém separado e com uma filha ilegítima. Apesar de a mãe impedir veementemente o namoro, Ana contraria a tudo e a todos, engravida e foge com seu amado para o interior Paulista.

A ousadia de Cora em enfrentar toda a sociedade, no início do século XX, denota sua personalidade que não se furtava de correr riscos, seu não conformismo, bem como perseverança diante dos obstáculos. Diversos estudos 
apontam que esta característica é comum a pessoas criativas (ALENCAR; FLEITH, 2003).

Instalam-se primeiro na cidade de Jaboticabal, São Paulo. Ana lê muito sobre direito e auxilia o esposo em suas defesas. Cantídio também aprecia leitura e concede a Ana clássicos literários como Anatole France, Fiodor Dostoievski, Eça de Queiroz, Ramalho Ortigão. Em um primeiro momento Cantídio orgulha-se da mulher.

\section{Fase Adulta}

Ana extrapola suas atividades de dona de casa e, mesmo concebendo cinco filhos, se envolve em serviços sociais. Consequentemente, o tempo fica pouco para seus versos e vai guardando na memória os acontecimentos da vida para um dia tentar botar no papel. Seus escritos restringem-se a artigos de jornais na expectativa de reivindicar melhorias para a sociedade que assiste. Neles passa a assinar como Cora Coralina.

Começa a escrever novamente quando reata a relação com a mãe. Em 1922 é convidada, por Monteiro Lobato, a participar da semana de arte moderna, mas é impedida pelo marido que, enciumado por sua projeção local, começa a implicar com seu trabalho literário. Mesmo assim, Ana vai produzindo e guardando seus escritos.

As leituras de Cora bem como suas variadas atividades e vivências podem ser vistas como um período de preparação para sua posterior criação literária. Deste modo, o que parece retardar seus escritos, na verdade, podem se constituir em subsídios para sua produção futura. Ideias incubadas podem "emergir" em um processo denominado de "iluminação", expressão esta referendada por diversos autores (ALENCAR; FLEITH, 2003)

Em 1934, o esposo de Cora falece. Para garantir a educação dos filhos, ingressa em diversas atividades para acarinhar fundos: comerciante, vendedora de livros na editora do amigo José Olímpio e, ainda, propõem um reflorestamento da cidade vendendo suas mudas de plantas e flores. Seus esforços não são em vão. Pôde ver os filhos se encaminharem em diversas carreiras como advocacia, serviço militar e educação

A criatividade não se restringe às artes. No ramo empresarial ser criativo não tem haver apenas com originalidade, mas requer idéias adequadas, possíveis de execução e que dêem nova abordagem ao produto. Neste raciocínio, Cora demonstra talento nos negócios ao dar nova nuance ao cultivo de 
suas plantas, solucionando seu problema financeiro e, também, beneficiando a cidade que reside (AMABILE, 1999)

Outros motivos pelos quais Cora era admirada pelos que a conheciam eram a generosidade e ausência de preconceito. Empregava para ajudar as pessoas e era conhecida por sua mesa larga, onde servia as pessoas juntas, não importando se eram os empregados ou não. Aprova o casamento da filha mais nova com um turco, por acreditar que a mistura de raças traz uma descendência melhor.

Este traço da personalidade de Cora, ou seja, ser alheia a preconceitos e discriminações, evidencia-se em estudos que afirmam que pessoas que desenvolvem seu potencial criativo ao longo da vida tornam-se mais flexíveis e abertas ao outro, o que lhes favorece um envelhecimento qualitativo (BARROS; BÚRIGO, 2005).

\section{Período da Longevidade}

Por várias razões esta pode ter sido a fase de ouro da escritora, devido às alegrias que se sucederão. Já com quase 60 anos, algo inusitado acontece. É pedida em casamento por um deputado que se maravilhava com suas idéias. Apesar da tentação e de sentir-se lisonjeada, não aceita.

Esta aparente autonomia afetiva de Cora, já que recusa uma proposta de casamento apesar de ter sido assombrada por toda a juventude pela possibilidade da solidão, pode ter sido fruto de sua educação permanente. Este exercício, que é um atributo indispensável a pessoas criativas, traz ganhos internos porque leva o indivíduo a uma constante autoavaliação. $\mathrm{O}$ autoconhecimento pode gerar um aumento nas relações interpessoais o que eleva a estima e, consequentemente, o sentimento de independência (BARROS; BURIGO, 2005).

Por motivos de herança, retorna à Goiás. Este fato a inspira de tal modo que amplia sua produção literária, recontando sua vida "em prosa e verso" (TAHAN, 1989). Também desenvolve outra atividade que a deixou famosa: doceira. Os sabores variavam entre passa de caju, doces glaceados de laranja da terra, figo e mamão verde.

A intensa retomada das atividades artísticas de Cora entra em consonância com estudos que discorrem sobre a necessidade do longevo retomar suas aptidões criativas, a fim de entender a si mesmo e trazer à tona suas potencialidades (BARROS; BÚRICO, 2005).

Seus clientes eram na maioria turistas e novos comerciantes que se instalavam em Brasília. Aos interessados em literatura, Cora distribuía seus 
versos, ouvindo de muitos destes que os editasse. Posteriormente conhece Dr. Tarquínio, advogado e escritor, que propõem levar seus originais para São Paulo. Ao se justificar que ainda precisava organizar sua papelada, o advogado a presenteia com uma máquina de datilografar para que o faça. Assim, aos 70 anos, ingressa em aulas de digitação. A convivência com os jovens a encanta e, em pouco tempo, está totalmente integrada. Finalmente, seus escritos são editados pela mesma editora que um dia trabalhara. Em julho de 1975, assim como outras importantes personalidades que ganharam destaque, após os 70 anos de idade, edita seu primeiro livro: Poemas dos Becos de Goiás.

O declínio da inteligência fluida (memória) que acontece a partir dos 70 anos, não é impedimento para pessoas que exercem a criatividade em domínios como a literatura, já que este tipo de produção está intimamente ligado às experiências e conhecimentos adquiridos ao longo da vida do escritor (NAKAMURA; CSIKSZENTMIHALYI, 2003). Estudos afirmam que idosos costumam destacar-se em criações que requerem reflexão e que denotam experiências e vivências (BARROS; BÚRICO, 2005).

Em 1976 edita seu $2^{\circ}$ livro: Meu livro de Cordel. Chovem homenagens e visitas de estudantes, fãs de suas obras. Ficava feliz ao ouvir dos jovens discentes que seus escritos lhes tocavam o coração. Em casa, sempre deixava exemplares de seus livros para vender aos fregueses, dedicando mensagens no lugar de autógrafos.

Um dos motivadores para que a pessoa continue a desenvolver sua criatividade, a despeito da idade, é a certeza de que sua produção faz diferença para outras pessoas, de que sua existência tem um sentido maior (NAKAMURA; CSIKSZENTMIHALYI, 2003). Por este motivo pesquisas discorrem sobre a importância da pessoa ser estimulada a desempenhar sua "missão criativa" a fim de alcançar motivação pessoal (BARROS; BÚRICO, 2005).

Aos 90 anos, em 1983, edita mais um livro que retrata sua infância: Vintém de Cobre. Destaca-se, em âmbito nacional, ao receber um elogio, feito pelo poeta Carlos Drummond de Andrade, que a classifica, em um artigo editado pelo jornal do Brasil, como a pessoa mais importante de Goiás:

"Minha querida amiga Cora Coralina: Seu "Vintém de Cobre" é, para mim, moeda de ouro, e de um ouro que não sofre as oscilações do mercado. É poesia das mais diretas e comunicativas que já tenho lido e amado. Que riqueza de experiência humana, que sensibilidade especial e que lirismo identificado com as fontes da vida! Aninha hoje não nos pertence. É patrimônio de nós todos, que nascemos no Brasil e amamos a poesia" (TAHAN, 1989). 
Para uma obra ser considerada criativa deve ser avaliada dentro do campo de conhecimento que abrange certo domínio. Os avaliadores são os juízes daquele campo de conhecimento que, no caso de Cora, se personifica na pessoa de Carlos Drummond de Andrade (ALENCAR; FLEITH, 2003).

Após este importante reconhecimento, torna-se mais famosa e recebe muitos convites para palestrar por várias partes do Brasil. Encanta-se com os jovens estudantes que se mostram fãs incondicionais. Este contato com a juventude a fortifica, como se pudesse lhe rejuvenescer. Quando era interpelada por eles sobre sua idade, sempre respondia: "Tenho todas as idades. Venho do século passado e continuo nascendo, me renovando, diariamente" (TAHAN, 1989, p. 152).

Pesquisas apontam que longevos criativos manifestam um alto grau de motivação intrínseca, pois têm como maior motivador para o desenvolvimento de suas criações, o prazer e o sentimento de que criar naquele domínio concede sentido às suas vidas. Autores classificam este sentimento como engajamento vital (NAKAMURA; CSIKSZENTMIHALYI, 2003).

Pessoas que gozam de engajamento vital emergem em outro processo nomeado em pesquisas como permanente. Este consiste em todo um aprofundamento de conhecimentos sobre o domínio, que começa bem posterior ao período da longevidade, tornando possível sua continuidade e culminância em idades mais avançadas (NAKAMURA; CSIKSZENTMIHALYI, 2003).

Na véspera de seus 94 anos, recebe o título de Doutora Onoris Causa, pela universidade de Goiás, admitindo ter sido esta a maior emoção de sua vida, prova de que valeu a pena persistir frente todo o preconceito e pressão familiar que sofrera. Em 1983, torna-se a primeira mulher a ganhar o prêmio de literatura Juca Pato, sendo premiada com festa grandiosa composta por intelectuais na cidade de São Paulo. Seu talento repercute também na televisão, em especial pela rede Globo, que exibe uma série televisiva, contando sua historia.

Segundo Nakamura e Csikszentmihalyi (2003) longevos criativos relatam envolvimento tal com o seu campo de conhecimento que com o passar do tempo sentem-se pertencentes aquele domínio de criação com a incumbência de perpetuá-lo.

Mesmo com mais de 90 anos, não perdeu o senso de humor ou o espírito de vanguarda. Segundo sua filha, ainda mostra interesse em fazer uma lipoaspiração por queixar-se do tamanho dos seios. Encoraja os netos a não desistirem de seus projetos quando estes não são aceitos, a seu exemplo, pois, ela mesma, se fosse desistir devido à desaprovação de outras pessoas, não seria quem era. 
Pesquisas apontam que longevos considerados criativos professam um sentimento de esperança e positivismo, valorizando as incertezas e não temendo o futuro (NAKAMURA; CSIKSZENTMIHALYI, 2003).

Falece em Goiânia, no dia 10 de abril de 1985, com 95 anos. Postumamente, ainda são editados dois de seus livros: Estórias da Casa Velha da Ponte e Os Meninos Verdes. Na sua pedra tumular deixa registradas as seguintes palavras: "Não morre aquele que deixou na terra a melodia de seu cântico na música de seus versos".

As palavras registradas por Cora refletem o sentimento captado por Nakamura e Csikszentmihalyi (2003) sobre a motivação criativa de poetas longevos. A maior seria o desejo de se juntar a outros escritores que foram imortalizados por suas obras. É possível que Cora compartilhasse do mesmo sentimento, na esperança de que seus escritos pudessem transcender a sua geração. Nada poderia ser mais verdade. Se assim o for, ela alcançou seu objetivo.

\section{Conclusão}

Muitos aspectos da vida de Cora podem ser comuns a todas as pessoas: as desilusões, as dores, os medos. Entretanto, o que fez dela uma pessoa criativa, de modo a transcender sua geração, foi sua capacidade de transformar percalços da vida em poesia.

Esta habilidade não se deu ao acaso. Foi fruto de decisões e comportamentos que a escritora desenvolveu ou tomou ao longo de sua vida. Assim, pessoas que desejam desenvolver-se criativamente devem começar a interar-se com o campo de seu estudo ainda na juventude. Fica evidente que a motivação intrínseca, ou seja, o desenvolvimento de uma tarefa por prazer ou por idealismo deve ser o motivo maior da criação. Por muito tempo, Cora não obteve conhecimento ou mesmo apoio financeiro por seus poemas. Ao contrário, persistiu em realizar aquilo que acreditava ser belo apenas pelo prazer e realização. Apesar de ter se alegrado com o reconhecimento dos juízes do domínio literário, já se sentia realizada com os elogios dos jovens que a visitavam em Goiás, buscando o doce de suas compotas e o aconchego de seus versos.

Desenvolver a criatividade não é apenas uma questão de aptidão, mas de qualidade de vida. Isto porque incorre em educação permanente, o que pode gerar, além dos conhecimentos adquiridos no campo que se quer desenvolver, ganhos emocionais.

Isto porque, desenvolver a criatividade, a exemplo de Cora Coralina, significa recriar a vida realizando aquilo que dá sentido a própria existência. 
Para ser criativo é preciso não se vender na juventude. Numa geração que cada vez mais vemos pessoas abastadas financeiramente, mas frustradas pessoalmente, desiludidas e deprimidas, a história de Cora, bem como as contribuições dos pesquisadores em criatividade, nos mostram que um caminho diferente pode ser trilhado, que a vida pode ser recriada.

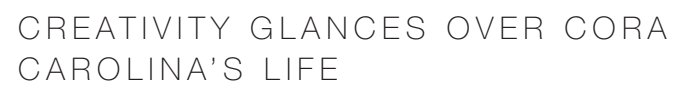

abstract

This article, developed in a form of a biographical study, intends to propagate some theories about creativity. It contains many contributions of authors in this subject, which theories dialogues with some aspects of Cora Coralina's life. One of the aims of this article is to call the reader's attention to the need and possibility to them to develop their own creativity, since that according to the studies shown, it is a potential possible to all people. Like this it is expected that the readers can make personal identification with some events of Cora Coralina's life, as well with some theories that are being presented in this article, to understand that even their difficulties and pains of common life can awake and nourish the creativity. Also, it is aim of this article to show the importance of exercising creativity to the development of the individual, especially when it is done as something pleasurable and with meaning, comprehending their intra and extra-personal aspects.

keywords

Creativity. Development. Cora Coralina. Longevity.

referências

ALENCAR, Eunice Soriano; FLEITH, Denise. Criatividade: Múltiplas Perspectivas. 3. ed. Brasilia: UNB, 2003.

AMABILE, Teresa M. Como não matar a criatividade. HSM Management, São Paulo, ano 2, n. 12, p. 111-115, jan./fev. 1999.

ANDRADE, Carlos Drummond. Cora Coralina, de Goiás. Jomal do Brasil. Rio de Janeiro, 31 dez.1979.

BARROS, Monize Ferreira A.; BÚRIGO, Silvana. Oficinas Pedagógicas no exercício da criatividade e educação permanente na velhice. Estudos Interdisciplinares Sobre o Envelhecimento, Porto Alegre, v. 7 p. 117-134, 2005. 
Recebido: 12/08/2012

Aceite final: 24/01/2013
MARTINS, Alexandra; ALENCAR, Eunice Soriano. Características desejáveis em professores de alunos com altas habilidades/superdotação. Revista Educação Especial, Santa Maria, v. 24, n. 39, p. 31-46, 2011.

NAKAMURA, Jeanne; CSIKSZENTMIHALYI, Mihaly. Creativity in Later Life. Oxford Press, USA, 2003.

TAHAN, Vivência. Cora Coragem Cora Poesia. 2. ed. São Paulo: Global, 1989. 